\title{
Economical Wastewater Treatment System for Automobile Service Stations in Sri Lanka
}

\author{
Munasinghe K.A. and Athapattu B.C.L.* \\ Department of Civil Engineering, Faculy of Engineering Technology, The Open University of Sri \\ Lanka, Nawala, Sri Lanka \\ *bandunee@yahoo.com
}

\begin{abstract}
Vehicle service stations use large quantities of water, oil and detergents for washing and servicing vehicles. Careful management of these effluents could minimize the ultimate disposal of untreated wastewater to the environment. In spite of the legitimate controls imposed by the Central Environment Authority, the disposals of untreated wastewater to the environment keep on increasing. It is justified by the distinctive oil spills seen in and around vehicle service stations in many parts of Sri Lanka.
\end{abstract}

On identifying the problem the necessity of developing a suitable system for wastewater treatment for vehicle service stations came to light. The objective was to develop an economical method to remove oil from wastewater and implement the developed method in vehicle service stations. To start with and to get a basic idea of similar methods used in other countries, literature survey was done. Field data collected using a questionnaire survey focusing vehicle service owners of Kalutara district. Wastewater effluent samples from vehicle service stations were collected and tested for the following parameters namely $\mathrm{pH}$, Temperature, TSS, BOD, Oil \& Grease and COD. On analysing the results it was found that there were four parameters that extensively exceeded the tolerance limits specified CEA. The analytical method used for determining the oil contents in wastewater was APHA method using Benzene.

The tolerance limits were exceeded by high margin due to the presence of Total Suspended Solids (TSS), Oil and Grease in wastewater effluents. Also high values were indicated for Biological Oxygen Demand (BOD) and Chemical Oxygen Demand (COD).

A prototype system to separate oil from wastewater was developed and tested at a vehicle service station. The system removed oil completely and directed the oil free wastewater into secondary treatment process. In addition to the separation of oil, the separator was able to settle suspended solids presence in the effluent. There were many methods adopted in vehicle service stations to cater for controlling BOD and COD such as aeration. As such this paper only concentrated on developing a suitable method for removing Oil and suspended solids and thus relieving the load on the secondary treatment process.

Keywords: Oil and grease, Vehicle service stations, Oil removal, Service station survey, Oil removal prototype 